\title{
The presentation, diagnosis and treatment of cervical osteoid osteoma
}

\author{
A. P. WALker \\ M.B., F.R.C.S. \\ Neurosurgical Unit of Guy's, Maudsley and King's College Hospitals
}

\begin{abstract}
Summary
A case of cervical osteoid osteoma is reported, with a brief account of the diagnosis and treatment of these lesions. Cervical osteoid osteoma is rare but its pattern of presentation varies little and it should therefore be possible to suspect it on clinical grounds alone. Bone scanning is now regarded as more efficient than radiography in identifying the lesion but X-ray tomography will normally be required for the accurate localization needed before surgery.

Correct surgical treatment results in complete cure.
\end{abstract}

\section{Introduction}

The term osteoid osteoma was first coined by Jaffe (1935). He regarded it as a benign tumour of bone and most subsequent authors have supported this contention.

Although the majority occur in the long bones, approximately $10 \%$ are located in the vertebral column (Paus and Kim, 1963), about one third of these in the cervical spine.

The delay in diagnosis of cervical osteoid osteoma, 8-20 months in a recent study of 4 patients (Fielding, 1977) and 6-7 years in the present case, can cause considerable suffering. This should be remembered as a cause of neck pain in children and young adults, particularly if the pattern of presentation is similar to the following.

\section{Case summary}

A 26-year-old student presented complaining of pain of 6-7 years' duration. It had first affected the right side of the neck and later spread along the radial border of the right upper limb. Initially the pain occurred only at night and would wake him regularly. Later, pain occurred during the day also. It was greatly relieved by salicylates. There was no certain weakness or sensory change in the right upper limb but the distribution of pain suggested a C6 root involvement.

A radioisotope scan showed an area of greatly increased activity in the cervical spine to the right of the midline at the level of Cv6 (Fig. 1).
Plain X-rays showed an abnormal area in the artic-官 ular process of $\mathbf{C 6}$ on the right with sclerosis affecting the right half of the body of that vertebra (Fig. 2). Anteroposterior, lateral and oblique tomograms. confirmed an area of sclerosis surrounding a zone of translucency with an opaque nidus at its centre. (Figs 3 and 4). The articular process was expanded by the lesion.

At operation an area of soft bone was curetted after $\vec{?}$ the overlying hard shell had been removed. When allo the soft area had been curetted, a scleroid-lined $\stackrel{\circ}{\circ}$ cavity remained. No instability resulted and there-fore fusion was not indicated. Histologically the lesion was a typical osteoid osteoma (Fig. 5). Pos operative X-rays, beyond confirming the operative. defect, showed no other changes (Fig. 6). In the fifft week after the procedure, the pain in the patient's? arm had eased considerably, 8 months later he is still pain free.

\section{Discussion}

Maclellan and Wilson (1967) found 10 cases in the literature and scattered reports have appeared since $\vec{T}$ (Ferrini, 1974; Heilbrun and Lehman, 1971; Salzer Kuntschik, 1974; Scott, Lignelli and Shea, 1971; Torok, 1970).

The reported lesions have always occurred in children or young adults (age range 7-28 years) and pre- $\underline{3}$. dominantly in males (M4 : F1). They always cause $ᄋ$ pain and the patient may be able to point to the skin $₹$ over the lesion as the point from which the pain o radiates. It may spread diffusely over the side of the neck or in the distribution of the nerve root adjacent to the lesion. Typically it occurs at night, at least initially, and in many cases is relieved by salicylates. or Although the distribution of the pain may point to a $N$ root lesion there are rarely any neurological signs $N$ present. Scoliosis may be present and is usually associated with a torticollis.

\section{Investigations}

Radioisotope bone scanning has been shown to demonstrate osteoid osteoma in many cases where $\bar{O}$ 


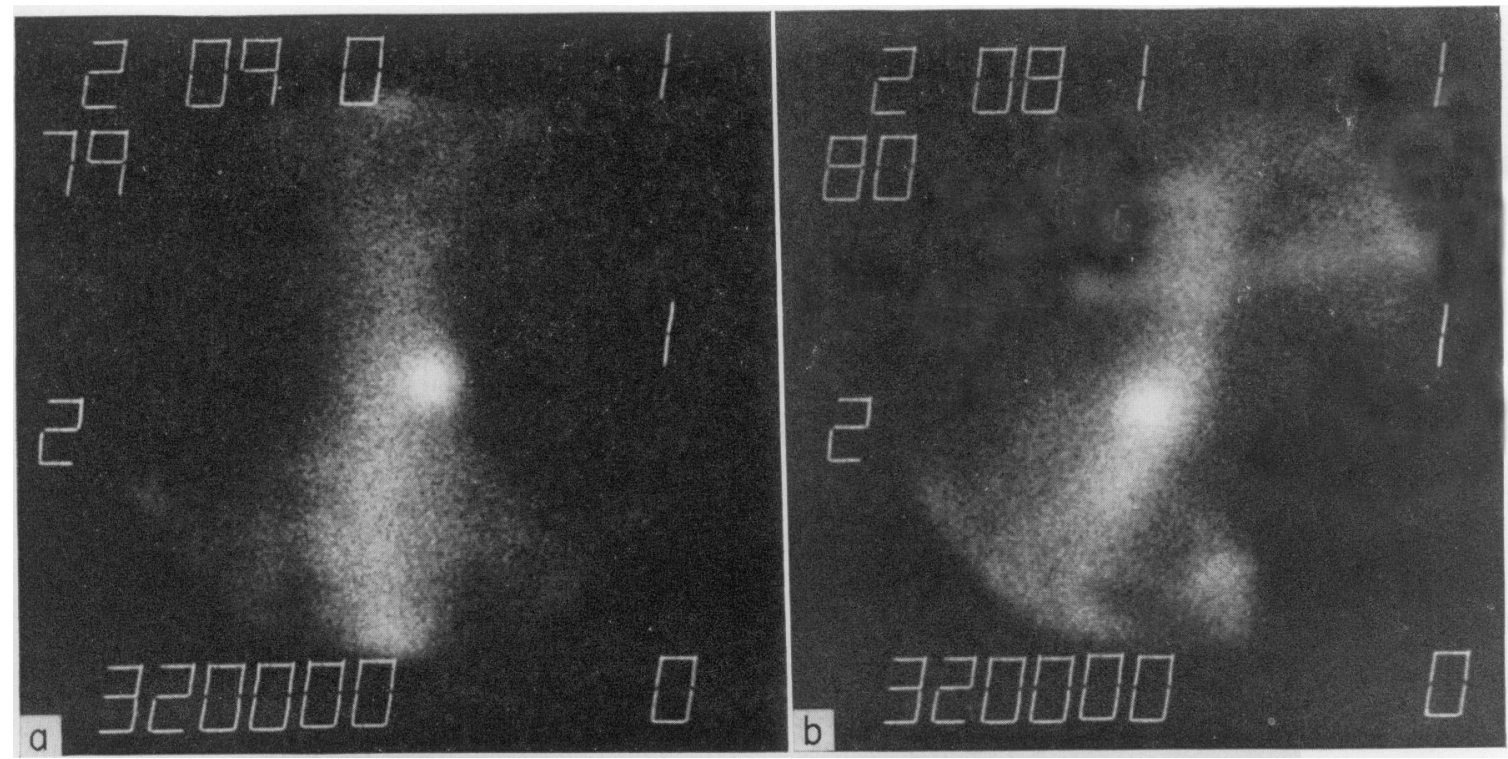

Fig. 1. Pre-operative anteroposterior and lateral radiophosphate bone scans showing area of intense concentration of isotope due to osteoid osteoma affecting 6 th cervical vertebra.

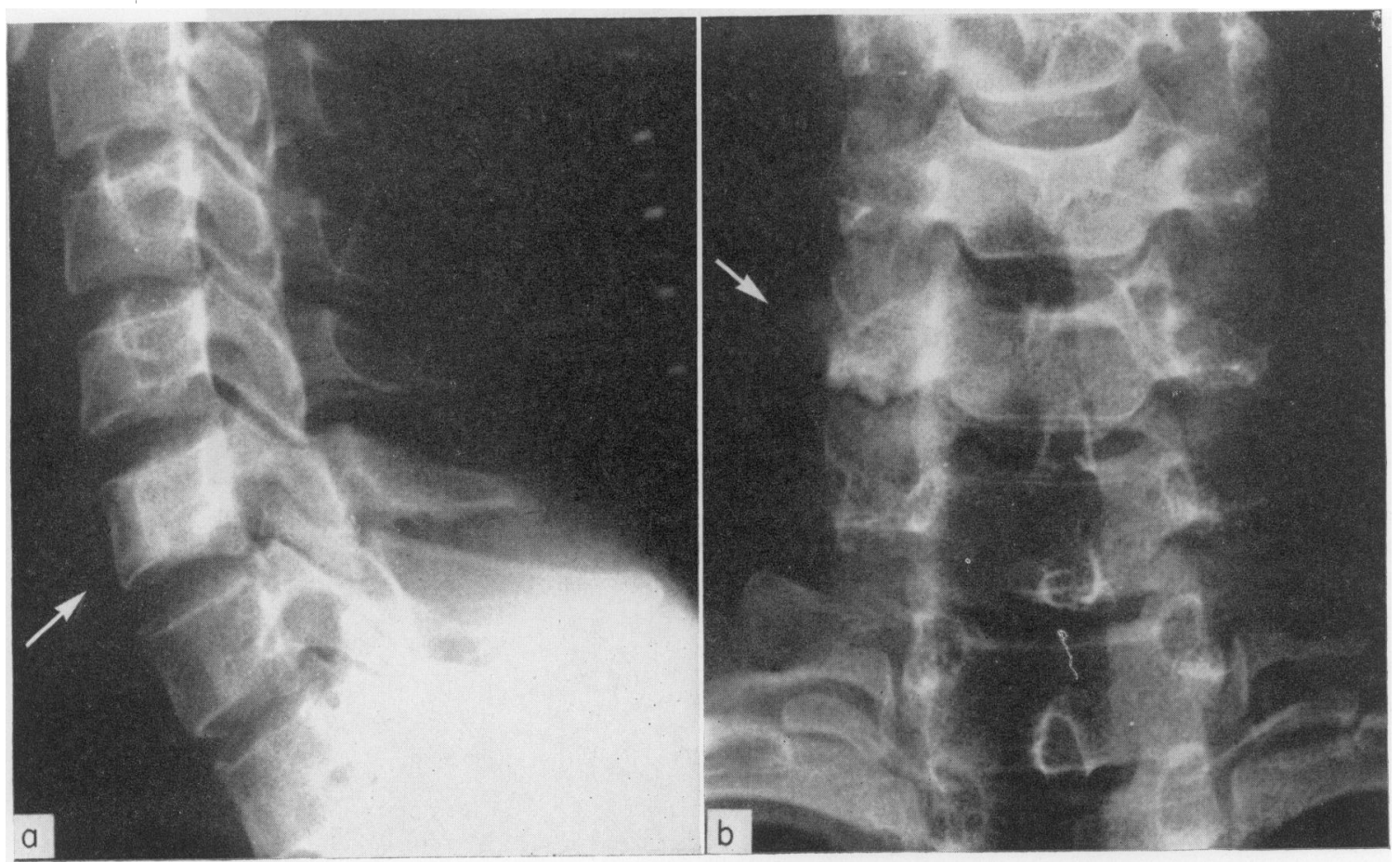

FIG. 2. (a) Lateral and anteroposterior X-rays of the cervical spine showing sclerosis affecting right half of the body of the 6th cervical vertebra with abnormal area in articular process. 
FIG. 3. Pre-operative lateral tomograms of cervical spine showing sclerosis in the right half of the body of the 6th cervical vertebra and an expanded articular process. 

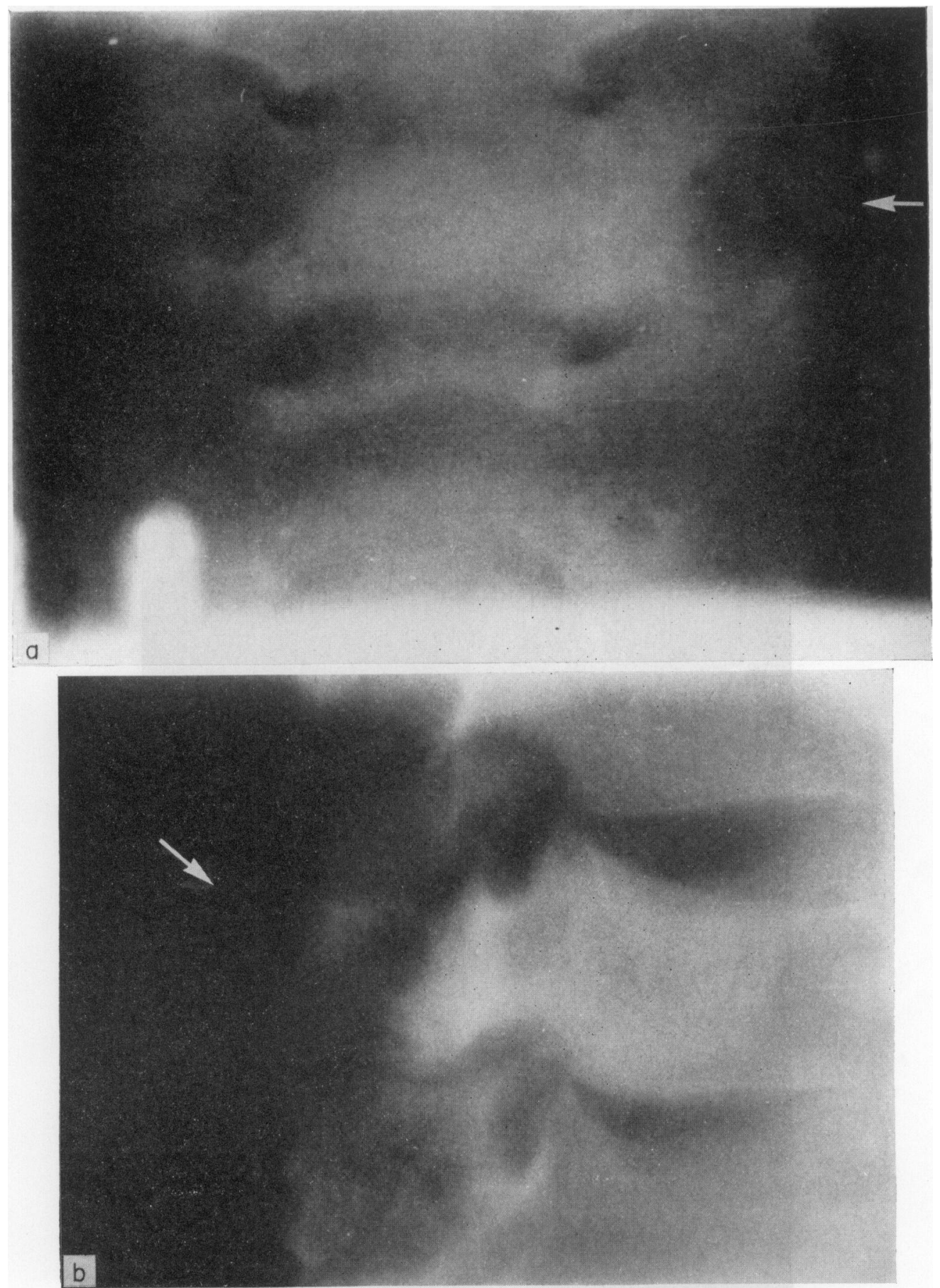

FIG. 4. (a) Pre-operative anteroposterior tomograms of cervical spine showing translucent zone with opaque nidus at its centre $(8.8 \mathrm{~cm}$ cut) and (b) surrounding sclerosis affecting articular process of 6 th cervical vertebra $(13.6 \mathrm{~cm}$ cut). 


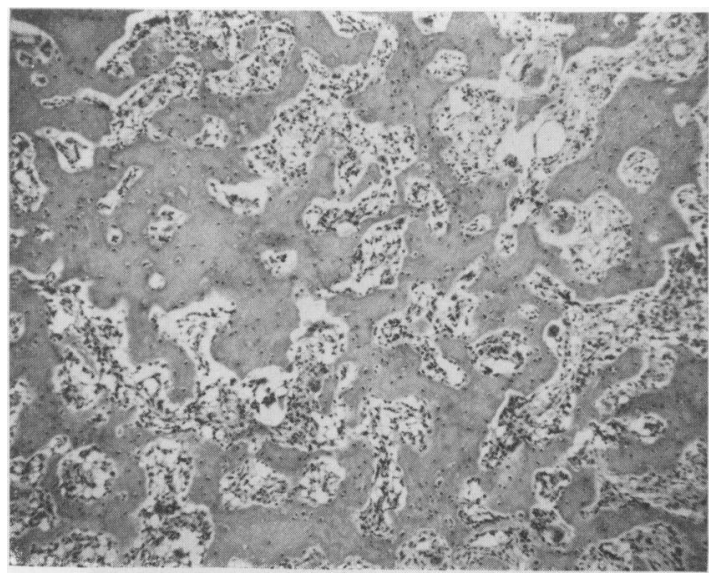

FIG. 5. Photomicrograph (magnification $\times 115$ ) showing the centre of the lesion consisting of an irregular mesh of osteoid trabeculae set in a vascular osteogenic connective tissue.
X-rays were negative (Lisbona and Rosenthall, 1979). The lesion is seen as an area of intensely abnormal $\mathbb{\otimes}$ concentration of the radioisotope. The typical X-ray $c$ appearance of a translucent zone surrounded by $\vec{F}$ sclerosis and with an opaque nidus at its centre may $\stackrel{5}{\rightarrow}$ not appear for months or years after the onset of $\bar{C}$ symptoms.

\section{Treatment}

Local curettage of the lesion is now accepted as curative. The nidus is found most often in the lamina, $\vec{\circ}$ less often in the spinous process, and rarely in the pedicle or vertebral body. It is therefore usually $\vec{\omega}$ approached posteriorly. Although the facet joint may be entered during the procedure, instability is rarely 8 produced and fusion is rarely necessary. Complete 3 relief of pain is invariably the result. The persistence $O$ of pain suggests the lesion is not fully excised.

\section{Acknowledgments}

I am grateful to $\mathrm{Mr}$ J.J. Maccabe, consultant neurosurgeon, Dr R. D. Hoare, consultant neuroradiologist, and Dr I.

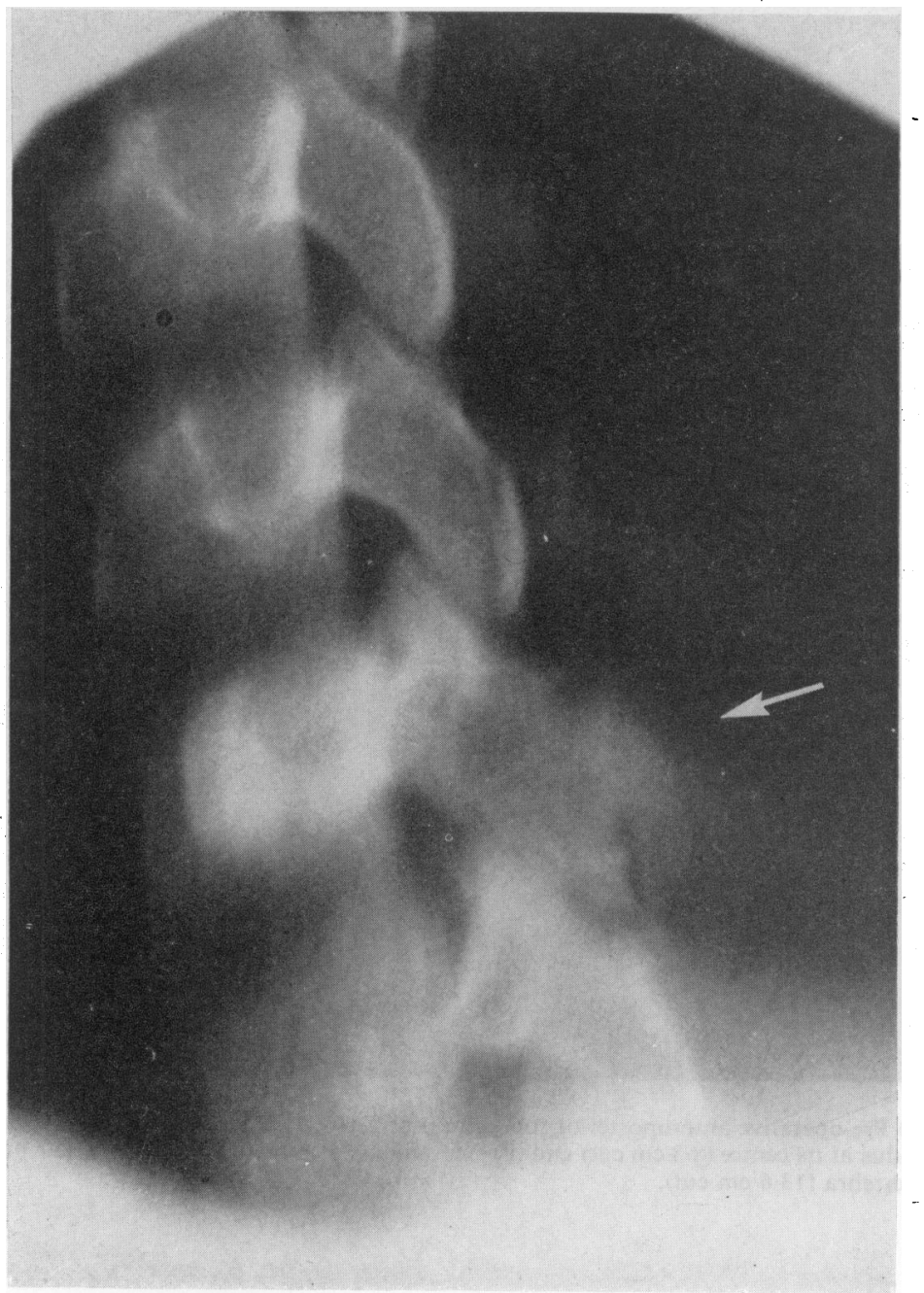


Janota, consultant neuropathologist, for their help in the preparation of this paper.

\section{References}

FERRINI, L. (1975) Cases of osteoid osteoma of the spinal column. Chirurgia degli organi di movimento, 72(2), 169.

Fielding, J.W., KeIM, H.A., HaWkins, R.J. \& Gabrielian, J.-C.Z. (1977) Osteoid osteoma of the cervical spine. Clinical Orthopaedics, 128, 163.

Heilbrun, M.P. \& Lehman, R.A.W. (1971) Osteoid osteoma of the cervical spine. Journal of Neurosurgery, $35,331$.

JAFFE, H.L. (1935) 'Osteoid osteoma' a benign osteoblastic tumor composed of osteoid and atypical bone. Archives of Surgery. Chicago, 31, 709.
Lisbona, R. \& Rosenthall, L. (1979) Role of radionuclide imaging in osteoid osteoma. American Journal of Roentgenology, 132(1), 77.

Maclellan, D.I. \& Wilson, F.C. (1967) Osteoid osteoma of the spine. Journal of Bone and Joint Surgery, 49A, 111.

Paus, B.S. \& KIM, T.K. (1963) Osteoid osteoma of the spine. Acta orthopaedica scandinavica, 33, 23.

Salzer KUNTSChIK, M. (1974) Osteoid osteoma of the right arch of 7 th cervical vertebra. Verhandlunger der deutschen Gesellschaft für Pathologie, 58, 251.

Scott, M. Lignelei, G.J. \& Shea, F.J. (1971) Cervical radicular pain secondary to osteoid osteoma of the spine. Journal of the American Medical Association, 217, 964.

Torok, G. (1970) Osteoid osteoma of cervical spine. Harefuah, 78, 395. 